Mohammad-Reza Ashory

Farhad Talebi

Heydar Roohi Ghadikolaei

Morad Karimpour

https://doi.org/10.21278/TOF.41404

ISSN 1333-1124

eISSN 1849-1391

\title{
AN INVESTIGATION INTO DIFFERENT POWER CONSUMPTION PARAMETERS OF RUSHTON TURBINES: A COMPUTATIONAL SURVEY
}

\begin{abstract}
Summary
In the present work, the mixing process of shear thinning liquids in a six-blade Rushton turbine is studied. A finite volume based computational fluid dynamics (CFD) simulation has been carried out and the three-dimensional turbulent flow is numerically analyzed by using the Shear Stress Transport k- $\omega$ (k- $\omega$ SST) model. Shear thinning liquids were investigated and shear thinning behaviour was modelled by the Ostwald-de Waele law. The used stirred vessel has a cylindrical shape with a flat bottom and the liquid height was kept equal to the vessel diameter. Effects of the power law index and the angle of attack of the blade on power consumption have been investigated. The results show that decreasing the angle of attack from $90^{\circ}$ to $45^{\circ}$ not only results in an increase in the flow rate down to the bottom of the vessel, resulting in a better mixture qualification, but also reduces the power consumption of the stirring process. To verify the simulation, axial, radial and tangential velocity components were compared with other experimental data and satisfactory agreement was found.
\end{abstract}

Key words: Rushton turbines, mixing vessel, shear thinning fluid, blade angle of attack

\section{Introduction}

Vessels that are agitated by mechanically rotating impellers are commonly used in industrial applications of chemical processes. This type of vessel, usually comprising a number of flat impellers in a cylindrical vessel, is employed for the purpose of stirring Newtonian and non-Newtonian fluids which usually exhibit shear thinning behaviour. In shear thinning fluids viscosity decreases when shear rate increases. As a consequence, the flow becomes turbulent at higher rotational speeds.

One of the first investigations that can be noted in the field of fluids in stirred vessels is the research by Hiraoka et al. [1]. The authors performed a 2D numerical study on Newtonian and non-Newtonian fluids generated by two-blade impellers and paddle agitators at a low impeller speed that shows that the flow is essentially tangential at a low impeller speed. In the same conditions, Bertrand and Couderc [2] performed experiments to study the performance of a large paddle impeller. Abid et al. [3] and Bouzit et al. [4] simulated 3D flow fields inside 
a tank filled with a Newtonian fluid and two-blade impellers at low Reynolds numbers. Youcefi [5] experimentally investigated the flow field power consumption and the mixing time induced by a large two-blade impeller for Newtonian and non-Newtonian fluids. Suzukawa et al. [6] investigated the effect of the angle of attack in four-bladed paddle impellers in a stirred vessel by applying the laser-Doppler velocimetry (LDV). Schäfer et al. [7] examined the turbulent flow structures generated by a four $45^{\circ}$ pitched blade impellers. The main aims of Aubin et al. [8] were to characterize the single phase turbulent flow in a tank stirred by a $45^{\circ}$ pitched blade impeller using CFD. Nouri and Hockey [9] presented the mean and rms velocity characteristics of the Newtonian and non-Newtonian flow in a mixing vessel stirred by a $60^{\circ}$ pitched blade impeller, measured by LDV. Venneker et al [10] examined the impact of the Reynolds number and the flow index for the turbulent flow and non-Newtonian fluid, experimentally and using LDV. Ameur and Bouzit [11] studied the effect of changing the length and width of the impeller used for stirring shear thinning fluids, focusing on the study of a two-blade impeller in the laminar flow. In the study of R. Zadghaffari et al. [12], a CFD software code was used to simulate the vessel agitated by a 6flat blade Rushton turbine. The fluid studied in this investigation is water, and large-eddy simulation (LES), i.e. the mathematical model for turbulence was used. Also, Z. Driss et al. [13] examined the simulation of a turbulent flow of water on pitched blade turbines, applying Navier-Stokes equations of the standard $\mathrm{k} \_\varepsilon$ turbulence model to the numerical simulation of the three-dimensional flow of fluid. Sing. $\bar{H}$. et al. [14] simulated the flow in a cylindrical tank agitated by a standard Rushton turbine by using k- $\varepsilon$, SST, SST-CC, SAS-SST and SSG-SM models. According to the authors, the SST model with curvature correction is the most satisfactory turbulence model tested for predicting turbulent flow in stirred tanks, in terms of both computing time and accuracy. Liu et al. [15] studied the performance of a large novel two-bladed impeller, which is based on Maxblend and Fullzone impellers. Zdenek Chara et al. [16] studied the turbulent flow simulation of a standard Rushton turbine using a detached eddy simulation (DES) in the water fluid. Also, the time-resolved PIV method was used to measure the angle-resolved velocity field near impeller blades in horizontal and vertical planes. Youcefi and Youcefi [17] measured the power consumption and the mixing time of a two-blade stirred tank during mixing viscoelastic fluids in the laminar region of the flow. Hamed Bashiri et al. [18] investigated turbulent fluid flows in stirred tanks using a nonintrusive particle tracking technique. The authors conducted a CFD simulation using RANSbased turbulence models of a 6 -flat blade Rushton turbine and a $45^{\circ}$ four-pitched blade turbine. Houari Ameur [19] examined the impact of changing the angle of attack on the stirring process in a two-impeller stir with a shear thinning fluid in the laminar flow regime. Petr Vlceka et al. [20] used a turbulence model of the large eddy simulation (LES) to simulate the flow in a fully baffled mixed vessel stirred by a $45^{\circ}$ pitched six-blade impeller with a water fluid.

In this paper, the effect of changing the angle of attack, the rotational speed and the type of fluid on the flow velocity components and power consumption is studied in a 6-blade stirred vessel without baffles. A numerical simulation of the turbulent flow is conducted for a shear thinning fluid using the CFX 16.2 (ANSYS-Inc.) software. Non-Newtonian fluid properties are modelled according to the Metzner and Otto concept and the turbulent flow regime is modelled with $\mathrm{k}-\mathrm{w}$ sst.

\section{System geometry}

The stirring system considered in this study is depicted in Fig. 3. As can be seen, the stirring tank is a cylindrical, flat-bottom vessel with a standard configuration and most of its dimensions are considered as a constant function of the tank diameter equal to $D=450 \mathrm{~mm}$. 
The impellors are modelled on a six-blade turbine whose diameter and clearance are $d=D / 3$ and $C=d$, respectively. The fluid height is considered equal to the tank height, i.e. $H=D$. The thickness of each blade is $3 \mathrm{~mm}$ and its length and height are $l_{\mathrm{b}}=D / 12$ and $h_{\mathrm{b}}=D / 15$, respectively. The diameter of the disk to which the blades are attached is $w=D / 4$ and the thickness is equal to $3 \mathrm{~mm}$. The shaft, having a diameter of $d_{\mathrm{s}}=D / 20$, is coaxial with the centerline of the cylinder. The angle of attack of the blades $(\theta)$ is considered equal to $45^{\circ}, 60^{\circ}, 75^{\circ}$ and $90^{\circ}$. The results of the simulation are presented in a nondimensional form, so that they could be extended to any arbitrary diameter of the tank.
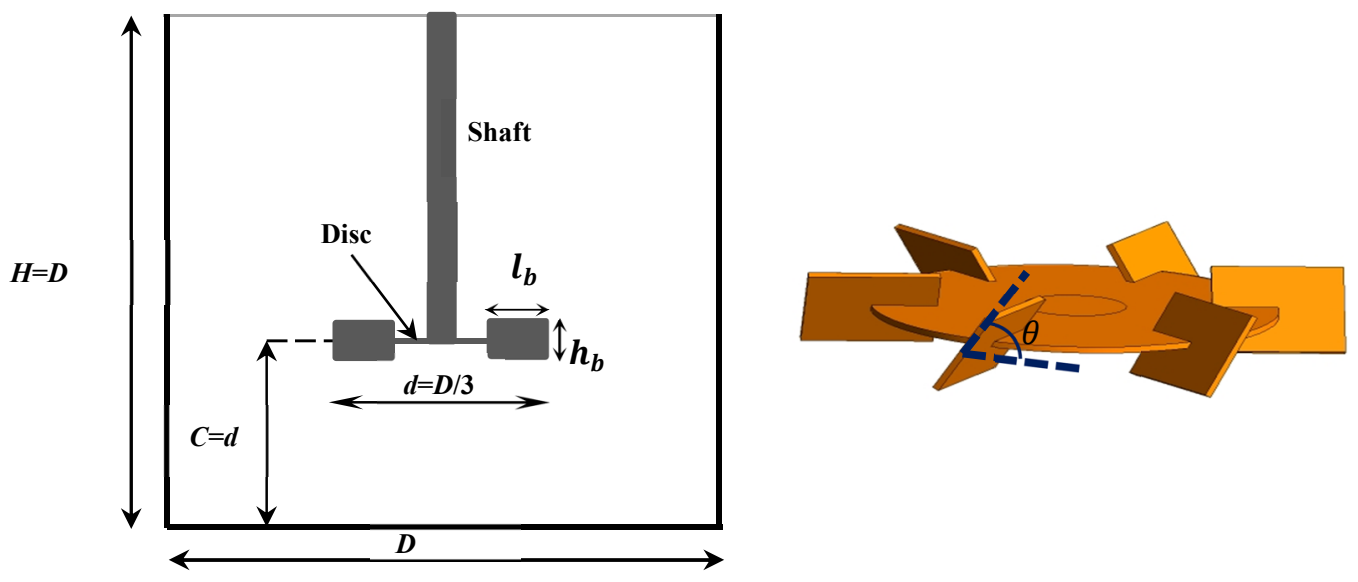

Fig. 1 Geometry of the mixing system and pitched blade angle $\theta$

\section{Numerical issues}

In this study, the commercial software CFX 16.2 (ANSYS-Inc) was used to simulate 3D flow fields in a stirred vessel equipped with a Rushton turbine. The Navier-Stokes equations were written in a rotating reference frame. Therefore, the centrifugal and the Coriolis acceleration terms are added. In this numerical study, the pressure at the center of each cell and the velocity components at the center of the six faces of the cell (one component on the two corresponding orthogonal faces) have been calculated. The pressure-velocity coupling is handled by the semi-implicit algorithm pressure linked equation (SIMPLE)described by Patankar [21].

The geometry was created by using ANSYS DesignModeler. The volume of the vessel was divided into two parts: the stationary (e.g., vessel) and the rotating part (e.g., impeller). There are three different approaches to solving such a problem, namely, the sliding mesh (SM) method, the mixing plane method and the multiple reference frame (MRF) method. Reviews on the subject can be found in R. Zadghaffari et al. [12]; Houari Ameur [19]; Hamed Bashiri et al. [18]. The MRF method could be used in our study since there are no baffles in the stirred tanks and large-scale transient effects are not present. In this method, the boundary conditions consist of setting each velocity component on the blades and the axial shaft equal to zero, because of the rotating frame, setting the angular velocity component at the vertical walls equal to the rotational speed, and the angular velocity on the bottom surface is chosen equal to $2 \pi N$.

Fig. 2 shows the mesh created by the ANSYS meshing software. The mesh size is reduced near the walls and the blades. To examine the independency of the mesh, several mesh configurations were analyzed, and finally, a mesh with 1,320,000 elements was selected so that the velocity changes of the blade tip were less than $2 \%$ with respect to the previous model that had 1,150,000 elements. 

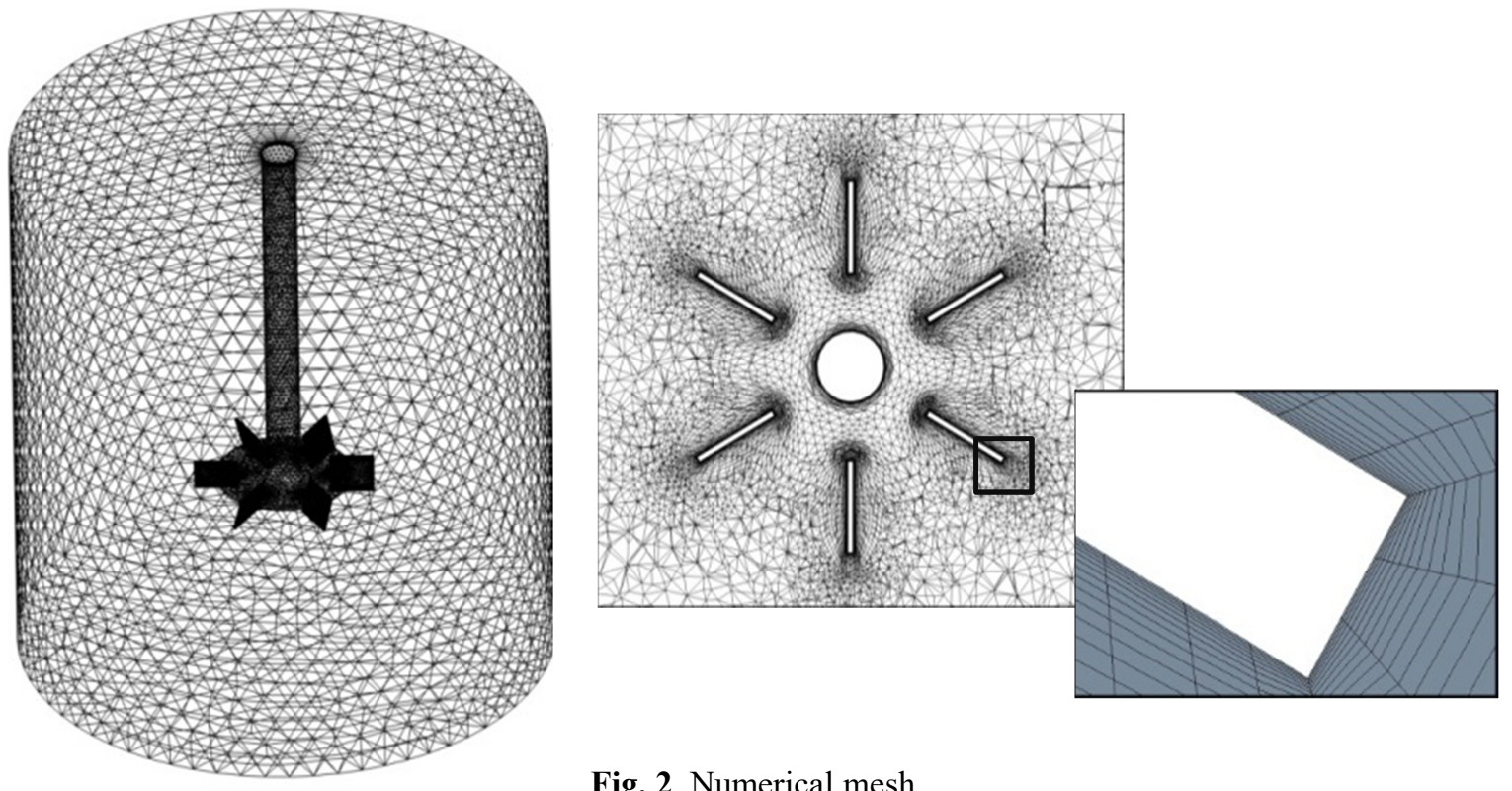

Fig. 2 Numerical mesh

\section{Rheological model}

In the present study, the simulations were carried out with non-Newtonian shear thinning fluids. Based on reports in the literature, two different types of polymers exist that do not exhibit elastic behaviour and the shear thinning behaviour was controlled by means of the weight percentage of the polymer added to the water. The first polymer is xanthan gum (Keltrol RD) and the second polymer is carboxy methyl cellulose (CMC) (Blanose). Xanthan gum is more shear thinning than CMC solutions. Rheological properties of the used fluids are based on the measurement performed by Venneker et al. [10] as given in Table 1.

The Metzner-Otto method [22] was used to obtain the average shear rate and the apparent viscosity was then calculated from the power law equation:

$$
\dot{\gamma}=\mathrm{k}_{\mathrm{s}} \mathrm{N}
$$

where $k_{s}$ is a weak function of the stirrer type which is equal to 11.5 for the Rushton turbine and $N$ is the impellor rotational speed. For a Newtonian fluid, the Reynolds number is given by:

$$
\operatorname{Re}=\frac{\rho \mathrm{Nd}^{2}}{\eta}
$$

in which $\eta$ is the effective viscosity coefficient with the unit of $P a . s$.

For a shear thinning fluid with the average shear rate from equation (1):

$$
R e=\frac{\rho N^{2-n} d^{2}}{m k_{s}^{n-1}}
$$

where $m$ and $n$ are the consistency index $\left(\mathrm{Pa}^{n}\right)$ and the power law index (dimensionless), respectively.

The power consumption, $P$, can be calculated in a stirred tank from the torque acting on the impeller [23] by:

$$
P=2 \pi N \tau
$$


where $\tau$ is the torque applied on the impeller. The power number, $N_{P}$, is then computed as:

$$
N_{P}=P / \rho N^{3} d^{5}
$$

Table 1 Rheological properties of the solutions.

\begin{tabular}{|l|c|c|c|}
\hline Solution & Concentration $(\%)$ & $\mathrm{m} \times 10^{-3}\left[\mathrm{~Pa} \mathrm{~s}^{\mathrm{n}}\right]$ & $\mathrm{n}[-]$ \\
\hline Water & - & 1.0 & 1.00 \\
\hline Blanose & 0.1 & 13.2 & 0.85 \\
\hline \multirow{3}{*}{ Keltrol } & 0.045 & 9.5 & 0.8 \\
\cline { 2 - 4 } & 0.08 & 34 & 0.64 \\
\cline { 2 - 4 } & 0.1 & 74.8 & 0.56 \\
\hline
\end{tabular}

\section{Results and discussion}

In order to validate the CFD model, the results were compared to those obtained by $\mathrm{Wu}$ and Paterson [24] and Venneker et al. [10] in their tests that had the same geometrical configuration. The fluid under study was water and the attack of angle of the blades was set to $90^{\circ}$. Fig. 3 presents the numerical velocity components (axial, radial and tangential) to the blade tip velocity $\left(\mathrm{V} / \mathrm{V}_{\text {tip }}\right.$ ) based on $\mathrm{R}^{*}$ (dimensionless radial coordinate, $\left.R^{*}=r / R\right)$ for the tank with a diameter of $450 \mathrm{~mm}$ and an angular velocity of $2.9 \mathrm{rev} / \mathrm{s}$, i.e. $\mathrm{Re}=65 \times 10^{3}$. In the software calculations, the origin of the coordinate system coincides with the disk center. Also, results were obtained for the xy-plane, for which $\mathrm{z}=0$. According to such findings, a good agreement exists between numerical and experimental results.



Fig. 3 Profiles of velocities at the impeller disc level $(\mathrm{Z}=0)$. 


\subsection{The effect of the angle of attack of the blades}

To evaluate the effect of the angle of attack $(\theta)$ on the shear thinning fluid stirring mechanism, the velocity field contour for the Blanose solution with a power law index of $n=0.85$ and $R e=90000$ is given in Fig. 4. The velocity field contour is drawn for two planes of the coordinate system, namely $\mathrm{YZ}$ and $\mathrm{XZ}$ and for four angles of attack: $45^{\circ}, 60^{\circ}, 75^{\circ}$ and $90^{\circ}$. It can be seen that the more the angle of attack is reduced from $90^{\circ}$ and approaches $45^{\circ}$, the more fluid is pumped toward the bottom of the tank and better stirring is achieved. As a consequence, according to the results, taking advantage of the pitched blade impeller is more effective in tanks having blades not close to the bottom of the cylinder and better stirring of fluids possessing higher viscosities is achieved. .

The power number $\mathrm{N}_{\mathrm{p}}$, calculated according to equation 5, is among important parameters studied in the stirring systems. The impact of the angle of attack on the parameter $\mathrm{N}_{\mathrm{p}}$ for the above mentioned fluid is depicted in Fig. 5. It can be observed from this figure that for a specific Reynolds number, the value of $\mathrm{N}_{\mathrm{p}}$ grows with an increase in the angle of attack, in such a way that when a flat blade Rushton turbine is used, this value rises to more than two times the value of the case whose the angle of attack of the blades is $45^{\circ}$. In other words, according to equation 5 , the power consumed for stirring the fluid decreases as the angle of attack decreases.


$\theta=90^{\circ}$
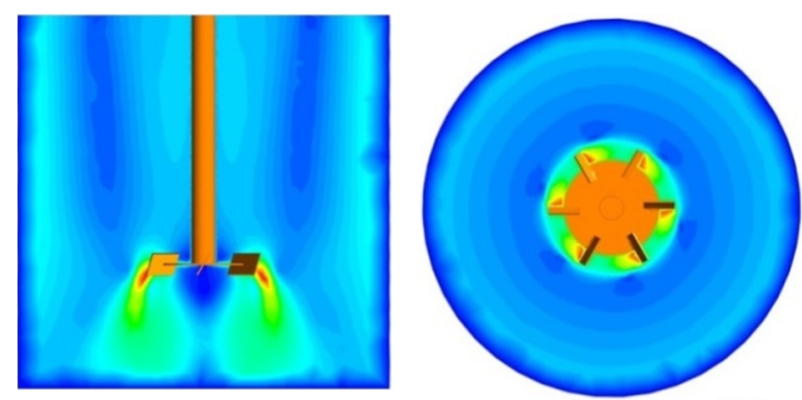

$\theta=60^{\circ}$


$\theta=75^{\circ}$

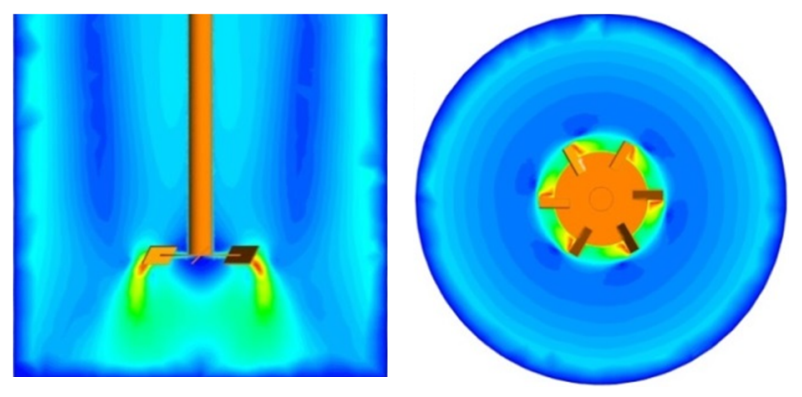

$\theta=45^{\circ}$

Fig. 4 Effect of the angle of attack of blades for Blanose solution with $\mathrm{n}=0.85$ and $\mathrm{Re}=90000$.

Fig. 6 shows the ratio of radial, tangential and axial velocities to the blade tip speed $\left(\frac{V}{V t i p}\right)$ based on the dimensionless distance from the blade tip $\left(R^{*}\right)$ for the Keltrol solution with $\mathrm{n}=0.8$ and $R e=150000$. As can be seen, the values of all three velocity parameters become lower as the angle decreases. The comparison between the radial velocity diagram obtained for the Keltrol solution and the one referring to water, Fig. 3, reveals that the radial velocity of the Keltrol solution in the region $R^{*}=1.0$ to 1.1 is different from the radial velocity of water. In other words, as the distance from the blade tip increases, the value of the 
radial velocity first increases and then decreases. By contrast, the radial velocity value for water, which is a Newtonian fluid, always drops as the distance from the blade tip increases. This result can be extended to other shear thinning fluids studied in this research.

It can be inferred from Fig. 6 that when increasing the distance from the impellers and getting closer to the vessel walls, all three velocity components diminish, although their reduction diagrams are not similar. Furthermore, in an approximate distance of $R^{*}=2.3$ to 3 , the value of the velocity components becomes almost the same for various angles of attack. Moreover, at this level of study $(z=0)$, the radial and tangential velocities approach zero as they get closer to the vessel wall. This is in contrast to the fact that the axial velocity has negative values in this region. In other words, the axial velocity which has a lower value than the other two velocity components approaches zero when increasing the distance from the impeller tip in the region $R^{*}=2.0$ to 2.3 and then it reaches a negative value. It is obvious from the figure that the smaller the attack angle is, the faster the axial velocity approaches zero and becomes negative.

\subsection{The effect of the rheological parameter}

In this section, the effect of fluid rheology on the stirring process is investigated. For this purpose, the variations of radial velocity for four different solutions are presented in Fig. 7. The results refer to the angle of attack of 90 degrees and the Reynolds number of 20,000 in the xy-plane $(z=0)$. As can be noticed, the radial velocity for water as a Newtonian fluid is greater than for shear thinning fluids. Moreover, for shear thinning fluids in the region $R^{*}=$ 1.0 to 1.1, with an increase in radius, the radial velocity first increases and then decreases until it reaches the vessel wall.

In addition, Fig. 8 depicts the power number $(N p)$ for different solutions given in Table 1 at the Reynolds number $=5,000$ and different angles of attack. It can be understood that as the power law index (n) increases, the power number at a specific angle and Reynolds number become greater in amount. It should be mentioned that rotational velocities for achieving a Reynolds number are not identical for different fluids. Rotational velocities required for reaching the Reynolds number of 5,000, for a tank of $450 \mathrm{~mm}$ and different solutions are shown in Table 2.



Fig. 5 Power number vs. angle of $\operatorname{attack}(\theta)$ for Blanose solution with $n=0.85$ and $\operatorname{Re}=90000$ 

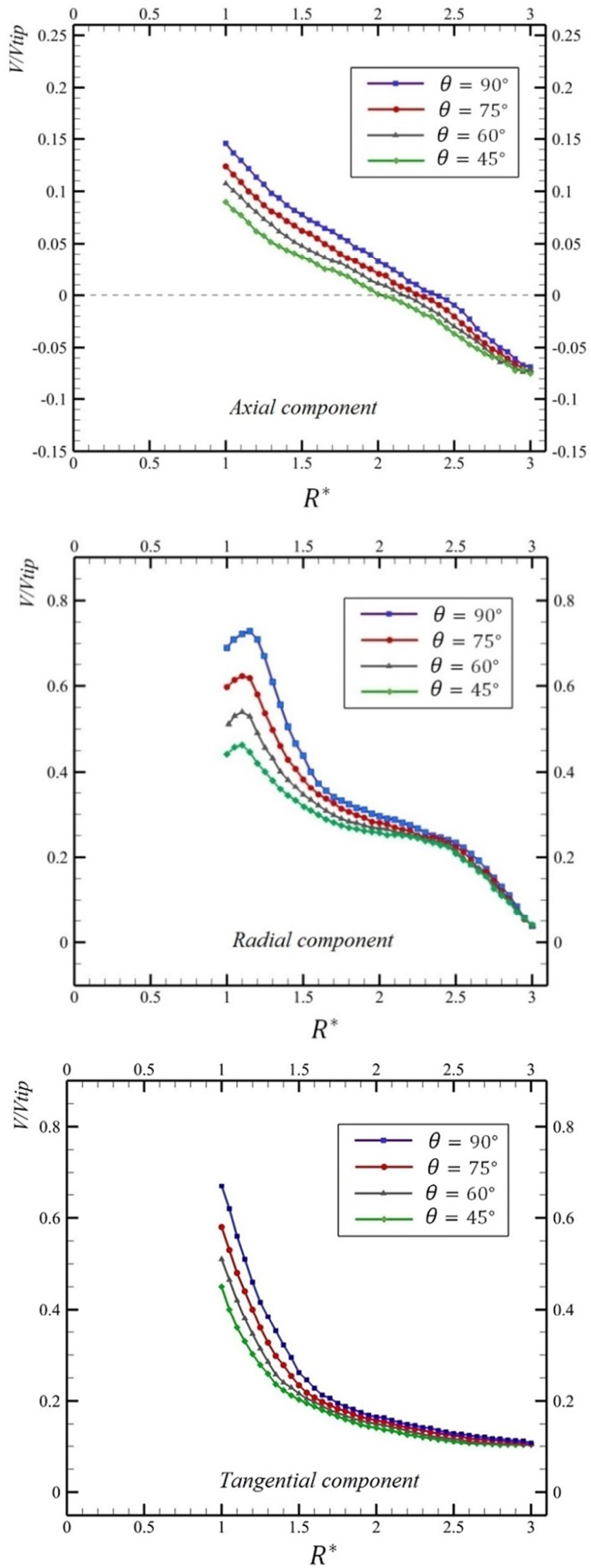

Fig. 6 Radial profiles of three velocity components at the impeller disc level $(\mathrm{z}=0)$ for Keltrol solution with $\mathrm{n}=0.8$ and $\operatorname{Re}=150000$. 


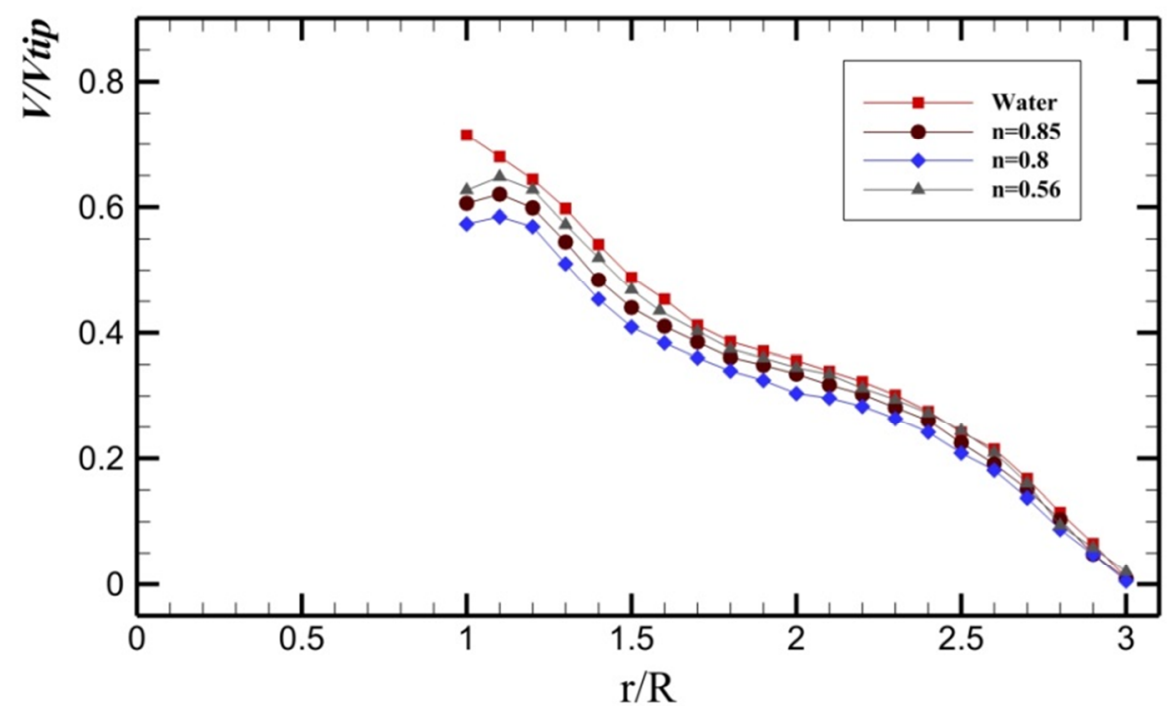

Fig. 7 Profiles of radial velocity for flat blade impeller $\left(\theta=90^{\circ}\right)$ at the impeller disc level $(Z=0)$ in $\operatorname{Re}=20000$.

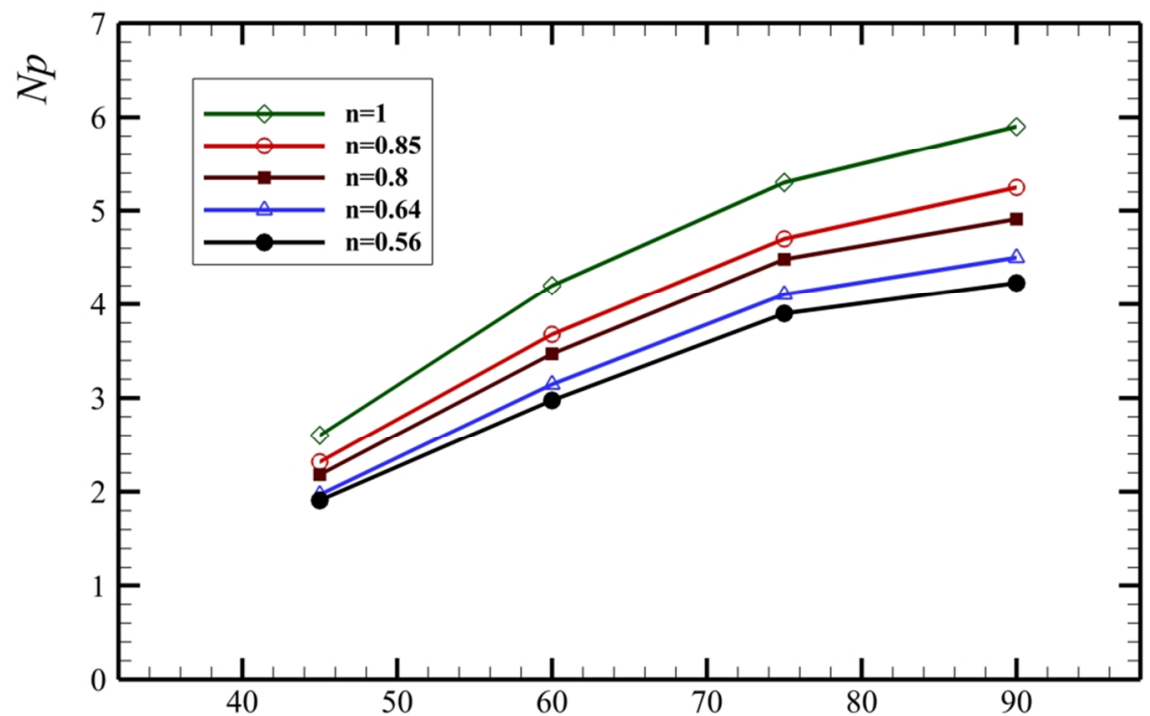

Fig. 8 Power number for shear thinning fluids and water in $\mathrm{Re}=5000$.

Table 2 Rotational speed for $R e=5000$.

\begin{tabular}{|l|c|c|c|c|}
\hline Solution & Concentration $(\%)$ & $\mathrm{m} \times 10^{-3}\left[\mathrm{~Pa} \mathrm{~s}^{\mathrm{n}}\right]$ & $\mathrm{n}[-]$ & $\mathrm{N}[\mathrm{rev} / \mathrm{s}]$ \\
\hline Water & - & 1.0 & 1.00 & 0.22 \\
\hline \multirow{3}{*}{ Blanose } & 0.1 & 13.2 & 0.85 & 1.85 \\
\hline \multirow{3}{*}{ Keltrol } & 0.045 & 9.5 & 0.8 & 1.25 \\
\cline { 2 - 5 } & 0.08 & 34 & 0.64 & 2.32 \\
\cline { 2 - 5 } & 0.1 & 74.8 & 0.56 & 3.34 \\
\hline
\end{tabular}




\section{Conclusion}

Today, the mixing process of non-Newtonian fluids is very conventional in various industries. In most of these cases the flow regime is turbulent. In this study, the effect of changing the angle of attack of blades in a six-blade Rushton turbine and the fluid shear thinning rheology in a turbulent flow are examined. The result of the computational fluid dynamics simulation shows that when decreasing the angle of attack from $90^{\circ}$ to $45^{\circ}$, more fluid will be pumped into the bottom of the vessel, resulting in a better mixture. Also, the power consumed when stirring a fluid is reduced when the angle of attack of the blades decreases.

\section{Nomenclature}

\begin{tabular}{|c|c|}
\hline$C$ & Impeller clearance $(\mathrm{m})$ \\
\hline$D$ & Impeller diameter (m) \\
\hline$D$ & Tank diameter $(\mathrm{m})$ \\
\hline$H$ & Vessel height (m) \\
\hline$h_{\mathrm{b}}$ & Blade height (m) \\
\hline $\mathrm{k}_{\mathrm{s}}$ & Metzner-Otto constant (dimensionless) \\
\hline$l_{\mathrm{b}}$ & Blade length (m) \\
\hline$M$ & Consistency index $\left(\mathrm{Pa}^{n}\right)$ \\
\hline $\mathrm{N}$ & Power law index (dimensionless) \\
\hline$N$ & Impeller rotational speed $(1 / \mathrm{s})$ \\
\hline $\mathrm{Np}$ & Power number (dimensionless) \\
\hline$P$ & Power $(\mathrm{W})$ \\
\hline$r$ & Radial coordinate $(\mathrm{m})$ \\
\hline$R$ & Impeller radius $(\mathrm{m})$ \\
\hline $\mathrm{R}^{*}$ & Dimensionless radial coordinate, $R^{*}=2 r / D$ \\
\hline$P$ & Fluid density $\left(\mathrm{Kg} / \mathrm{m}^{3}\right)$ \\
\hline$H$ & Effective viscosity coefficient $(P a s)$ \\
\hline $\operatorname{Re}$ & Reynolds number \\
\hline$\dot{\gamma}$ & Shear rate $(1 / \mathrm{s})$ \\
\hline$\theta$ & Blade attack angle (degree) \\
\hline$T$ & Torque $(\mathrm{N} \mathrm{m})$ \\
\hline
\end{tabular}

\section{REFERENCES}

[1] Hiraoka, S., I. Yamada, and K. Mizoguchi, Two dimensional model analysis of flow behaviour of highly viscous non-Newtonian fluid in agitated vessel with paddle impeller. Journal of Chemical Engineering of Japan, 1979. 12(1): p. 56-62. https://doi.org/10.1252/jcej.12.56

[2] Bertrand, J. and J. Couderc, Evaluating of the power consumption in agitation of viscous newtonian or pseudoplastic liquids by two-bladed, anchor or gate agitators. Chemical engineering research \& design, 1985. 63(4): p. 259-263.

[3] Abid. M, C.X. and B. J, Modeling of the 3D hydrodynamics on 2-blades impellers in stirred tanks filled with a highly viscous fluid. Can J Chem Eng 1994. 72: p. 184-193.

https://doi.org/10.1002/cjce.5450720202 
[4] Bouzit, M., et al., CFD simulations of the 3D velocity profile of paddle agitator and two-blade impeller in stirred vessel with a highly viscous Newtonian fluid. Journal of Applied sciences, 2006. 6(13): p. 27332740. https://doi.org/10.3923/jas.2006.2733.2740

[5] Youcefi, A., Experimental study of viscoelastic fluid flow around two-blade impeller in a stirred vessel. 1993, PhD Thesis.

[6] Suzukawa, K., S. Mochizuki, and H. Osaka, Effect of the attack angle on the roll and trailing vortex structures in an agitated vessel with a paddle impeller. Chemical engineering science, 2006. 61(9): $\mathrm{p}$. 2791-2798. https://doi.org/10.1016/j.ces.2005.10.063

[7] Schäfer, M., Yianneskis, M., Wächter, P. and Durst, F., Trailing vortices around a $45^{\circ}$ pitched-blade impeller. AIChE Journal, 1998. 44(6): p. 1233-1246. https://doi.org/10.1002/aic.690440602

[8] Aubin, J., D.F. Fletcher, and C. Xuereb, Modeling turbulent flow in stirred tanks with CFD: the influence of the modeling approach, turbulence model and numerical scheme. Experimental thermal and fluid science, 2004. 28(5): p. 431-445. https://doi.org/10.1016/j.expthermflusci.2003.04.001

[9] Nouri, J. and R. Hockey, Flow characteristics of Newtonian and non-Newtonian fluids in a vessel stirred by a $60^{\circ}$ pitched blade impeller. The International Journal of Multiphysics, 2008. 2(1): p. 83-105. https://doi.org/10.1260/175095408784300261

[10] Venneker, B.C., J.J. Derksen, and H.E. Van den Akker, Turbulent flow of shear-thinning liquids in stirred tanks - The effects of Reynolds number and flow index. Chemical Engineering Research and Design, 2010. 88(7): p. 827-843. https://doi.org/10.1016/j.cherd.2010.01.002

[11] Ameur, H. and M. Bouzit, Power consumption for stirring shear thinning fluids by two-blade impeller. Energy, 2013. 50: p. 326-332. https://doi.org/10.1016/j.energy.2012.11.016

[12] Zadghaffari, R., J. Moghaddas, and J. Revstedt, Large-eddy simulation of turbulent flow in a stirred tank driven by a Rushton turbine. Computers \& Fluids, 2010. 39(7): p. 1183-1190. https://doi.org/10.1016/j.compfluid.2010.03.001

[13] Driss, Z., et al., Computational studies of the pitched blade turbines design effect on the stirred tank flow characteristics. European Journal of Mechanics-B/Fluids, 2010. 29(3): p. 236-245. https://doi.org/10.1016/j.euromechflu.2010.01.006

[14] Singh, H., D.F. Fletcher, and J.J. Nijdam, An assessment of different turbulence models for predicting flow in a baffled tank stirred with a Rushton turbine. Chemical Engineering Science, 2011. 66(23): p. 5976-5988. https://doi.org/10.1016/j.ces.2011.08.018

[15] Liu, B., et al., The influence of feeding location on the micromixing performance of novel large-doubleblade impeller. Journal of the Taiwan Institute of Chemical Engineers, 2015. 52: p. 65-71. https://doi.org/10.1016/j.jtice.2015.02.012

[16] Chara, Z., Kysela, B., Konfrst, J. and Fort, I., Study of fluid flow in baffled vessels stirred by a Rushton standard impeller. Applied Mathematics and Computation, 2016. 272: p. 614-628. https://doi.org/10.1016/j.amc.2015.06.044

[17] Youcefi, S. and A. Youcefi, Power consumption and mixing time in rheologically complex fluids by a two-bladed impeller. Journal of Mechanical Science and Technology, 2015. 29(2): p. 543-548. https://doi.org/10.1007/s12206-015-0114-1

[18] Bashiri, H., Alizadeh, E. and Chaouki, J., Investigation of turbulent fluid flows in stirred tanks using a non-intrusive particle tracking technique. Chemical Engineering Science, 2016. 140: p. 233-251. https://doi.org/10.1016/j.ces.2015.10.005

[19] Ameur, H., Mixing of complex fluids with flat and pitched bladed impellers: Effect of blade attack angle and shear-thinning behaviour. Food and Bioproducts Processing, 2016. 99: p. 71-77. https://doi.org/10.1016/j.fbp.2016.04.004

[20] Vlček, P., et al., Large eddy simulation of a pitched blade impeller mixed vessel-Comparison with LDA measurements. Chemical Engineering Research and Design, 2016. 108: p. 42-48. https://doi.org/10.1016/j.cherd.2016.02.020

[21] Patankar, S.V., Numerical heat transfer and fluid flow: Computational methods in mechanics and thermal science. 1980.

[22] Metzner, A. and R. Otto, Agitation of non-Newtonian fluids. AIChE Journal, 1957. 3(1): p. 3-10. https://doi.org/10.1002/aic.690030103 
[23] Gimbun, J., Rielly, C., Nagy, Z. and Derksen, J. J., Detached eddy simulation on the turbulent flow in a stirred tank. AIChE Journal, 2012. 58(10): p. 3224-3241. https://doi.org/10.1002/aic.12807

[24] Wu, H. and G. Patterson, Laser-Doppler measurements of turbulent-flow parameters in a stirred mixer. Chemical Engineering Science, 1989. 44(10): p. 2207-2221.

https://doi.org/10.1016/0009-2509(89)85155-3

Submitted: $\quad 12.11 .2016$

Accepted: $\quad 12.6 .2017$
Assoc. Prof. Mohammad-Reaz Ashory

Assist. Prof. Farhad Talebi

Phd Student. Heydar Roohi Ghadikolaei

Department of Mechanical Engineering

Semnan University

Semnan Iran

Assist. Prof. Morad Karimpour

Department of Mechanical Engineering,

Tehran University

Tehran Iran 